\title{
COVID-19 in East and Southern Africa: Rebuilding Differently and Better Must Start Now
}

\section{Rene Loewenson $\mathrm{PhD}(\mathrm{Med}) \mathrm{MScCHDC}$}

By June 2020, the cumulative cases and deaths related to COVID-19 in 16 East and Southern African (ESA) countries were still rising, with an average case fatality rate of $1.46 \% .[1]$ From its initial presence in cities and regional transport hubs, cases are spreading, including to rural areas, among health workers and as migrants cross borders to return home.[2]

The pandemic has highlighted important public health deficits in the region. While hand washing with soap is a key intervention, in 12 ESA countries fewer than $50 \%$ of their populations can access safe water and hand-washing facilities. While many ESA countries implemented early lockdowns, high levels of socioeconomic inequality and precarious employment make them difficult to sustain, as income and food security depend on working daily. Testing for, tracing and quarantining cases work when tests are available and results can be returned quickly. Yet ESA countries have not been able to access sufficient test kits or reagents.[3] Although testing levels in these countries increased to an average of 1800 tests per million people by June 12 (excluding higher levels in Botswana, Mauritius and South Africa), this is well below levels in countries such as South Korea that have effective test and trace strategies.[1]

For ESA countries, COVID-19 has exposed the weakness in being dependent on research and production outside the region of commodities that are needed in good time for communities and services across the region. This not only relates to current demand, like test kits. It forewarns that African countries will be last in the queue when COVID-19 treatments and vaccines are approved. Tariff reductions and reduced protections for domestic industry have suited a global strategy of 'lowest-cost-production' but leave ESA countries vulnerable in the global competition for products. The UN Economic Commission for Africa (UNECA) reports that $94 \%$ of Africa's total pharmaceutical stock is imported.[4] With at least 71 countries having imposed limitations or outright bans on exports of certain COVID-19 essential supplies, UNECA observes that this imperils Africa's access to these supplies. ESA countries have thus argued for the policy space to use existing Trade Related Aspects of Intellectual Property Rights (TRIPS) flexibilities for national and regional procurement and production, and for global support for open innovation and manufacturing, to encourage local or regional production to meet the demands related to the pandemic.[3]

COVID-19 has also pointed to resources in the region that could play a more significant role in public health. A high level of literacy, social networking and growing mobile phone uptake are potential assets for community-led social responses to COVID-19, if supported. For example, musicians in Tanzania and Uganda spread COVID-19 messaging, and communities provide solidarity support via South Africa's Together Community Action Network. Meanwhile, innovation by informal enterprises has stimulated the production of face masks, personal protective equipment and other appropriate technologies for health, while formal enterprises, including universities, have

repurposed production lines and launched new product lines to supply face shields and ventilation equipment for health services. There are medicine production capacities on the continent, boosted by South-South partnerships. Community health workers (CHWs) are present in all ESA countries and drawing on experience from the Ebola epidemic, CHWs are being trained in some countries as trusted sources of information for community literacy and to support COVID-19 prevention and case detection.[2]

The Ebola experience showed that an effective response demands collaborative work that involves communities and is supported by professionals, governments and accessible, capable public services. This is the same lesson learned from the gains made in health by applying primary health care strategies in the region, despite their being weakened by underfunding of public services.

In contrast, the response to COVID-19 has often generated a self-protective response across countries in global trade and a command-and-control response within countries. Yet neither are effective strategies for a global pandemic that demands distributed local capacities and action.

Building production
capacities in the region
calls for international
collaborations and
partnerships that support
open innovation and open
production

global public goods, notwithstanding the public funding this R\&D often receives. It is surely a lesson from COVID-19 that ESA countries cannot continue to rely on importing commodities that are vital for managing epidemics. Building production capacities in the region calls for international collaborations and partnerships that support open innovation and open production, recognizing the mutual health security gained from sharing technical inputs that stimulate a distributed production, while closing the gap between production sites and population need.

Notwithstanding the resources mobilized for the regional response to COVID-19 at all levels, the scale of these responses and the pandemic's economic damage call for deeper and more sustained financing. African ministers of finance have called for an estimated US $\$ 44$ billion to be released for this by suspending interest payments on debt and sovereign bonds and cancelling debt for the poorest countries, a call also made by UN Secretary-General António Guterres.[3]

There is a sense that our response cannot be 'business as usual.' Opening the 2020 World Health Assembly, UN Secretary-General Guterres described "the recovery from the COVID-19 crisis" as an opportunity "to rebuild differently and 
better." This begins with how we respond to COVID-19 today. "Differently and better" includes significantly greater investments in infrastructures, services and pandemic responses within countries that meaningfully engage with communities and address the fundamentals for healthy societies. It includes forms of international cooperation that ensure essential health technologies and capacities for effective pandemic responses can be produced in all regions where they are needed. $-1 /$ -
1. Worldometer [Internet]. [place unknown]: Worldometer; c2020. Coronavirus. COVID-19 CORONAVIRUS PANDEMIC; [updated 2020 Jun 26; cited 2020 Jun 12]. Available at: https://www.worldometers.info/coronavirus/

2. World Health Organization. COVID-19. The Situation update for the African Region. External Situation Report 15. Geneva: World Health Organization; 2020 [cited 2020 Jun 15]. 11p. Available at: https://apps.who.int/iris/bitstream/ handle/10665/332321/SITREP COVID-19 WHOAFRO 20200610-eng.pdf

3. East Central and Southern African Health Community (ECSA HC); EQUINET: TARSC; SEATINI. Brief: Securing COVID-19 related diagnostics, health technology, medicines and vaccines for African public health, May 2020 [Internet]. Brussels: EQUINET; 2020 [cited 2020 Jun 15]. 11p. Available at: https://www .equinetafrica.org/sites/default/files/uploads/documents/EQ\%20ECSA\%20 brief\%20COVID19\%20health\%20tech\%20May2020.pdf

4. United Nations Economic Commission for Africa (UN ECA). COVID-19 in Africa: Protecting Lives and Economies, UN ECA, Addis Ababa: United Nations Economic Commission for Africa (UN ECA); 2020 [cited 2020 Jun 15]. 48 p. Available at: https://www.uneca.org/sites/default/files/PublicationFiles/eca covid_report_en_24apr_web1.pdf

\section{ACKNOWLEDGMENTS}

The views expressed are my own. I gratefully acknowledge the interactions with colleagues in the region and in EQUINET, particularly Riaz Tayob, Rangarirai Machemedze, Yoswa Dambisya, Willy Were, Patrick Bond and Thandiwe Loewenson.

Submitted: June 17, 2020

Approved for publication: June 26, 2020

Disclosures: none

Correspondence: rene@tarsc.org https://orcid.org/0000-0002-9928-540X 